\title{
CHRONIC CARBON TETRACHLORIDE INTOXICATION
}

\author{
BY
}

\author{
ALICE STEWART and L. J. WITTS
}

\author{
(From the Nuffield Department of Clinical Medicine, University of Oxford)
}

Carbon tetrachloride is a non-inflammable, cheap and easily available fat solvent. The majority of cases of poisoning reported have been isolated incidents, following temporary exposure to high concentrations of the vapour or oral administration of liquid carbon tetrachloride in the treatment of disease. In such cases death may result from narcosis, hepatic necrosis or acute nephritis but if the victim survives, little or no permanent damage ensues. There has been little reason to suppose that workers in contact with carbon tetrachloride suffer any deterioration in general health, so long as precautions to prevent heavy exposure have been taken in designing the plant. This opinion appeared to be confirmed by the investigations of Smyth and Smyth (1936) among workers employed in thirtysix factories using carbon tetrachloride. They made a careful analysis of air concentrations of the solvent and carried out a series of blood counts, and liver and kidney function tests, on ninety-six workers who had been employed over several years. They concluded that their tests showed that no one could be considered seriously or even unmistakably injured by the solvent vapours.

It was therefore a matter of considerable interest when we were asked to carry out an investigation in a chemical factory where large numbers of workers were said to be suffering from chronic carbon tetrachloride poisoning. Although only 75 people were working at any one time in contact with carbon tetrachloride, 122 certificates for compensation had been issued over a period of two-and-a-half years and more than 80 people had been discharged because of symptoms attributed to carbon tetrachloride. The work was acquiring an evil reputation in the district and it was becoming increasingly difficult to obtain labour to replace the losses. In addition the management was perturbed by failure to maintain a satisfactory rate of production. In work of this kind efficiency can be measured by the ratio between output and input of chemicals. In a new process it is customary for the ratio to rise sharply at first as the technique is mastered, and thereafter to maintain a slight upward trend. In this particular process the numerical value for efficiency had actually declined. This was attributed to the failure of shift managers and key personnel to maintain enthusiasm or even carry on at all after six to eighteen months in contact with carbon tetrachloride.

\section{Details of Investigation}

The process consisted in the chlorination of an aniline derivative in solution in carbon tetrachloride. The factory had been planned for continuous work under conditions of war, and more attention had been paid to the strength of the walls and the completeness of the black-out than to the state of the atmosphere. Apart from the difficulty of general ventilation, high concentrations of carbon tetrachloride were liable to occur from spills of material and from leaks in the piping system which connected the separate containers or conveyed the mother liquor from the sump tank back to the still house. Such leaks were inevitable owing to corrosion of pipes by traces of hydrochloric acid and the solvent action of carbon tetrachloride on the washers of joints and pumps. The chlorinated compound was eventually separated from the carbon tetrachloride by centrifuging and vacuum drying and during these processes an ill-fitting lid or an inefficient draught was enough to contaminate the atmosphere heavily. No useful figures can be given for the air concentrations of carbon tetrachloride. Although the chemists used the Halide Detector Lamp over a period of three months, it did not work satisfactorily and if a serious leak occurred, no one was free to take a reading. At first it was thought that the high morbidity rate might be due to some other chemical used in the process. But an analysis of the air concentration of the various substances and a comparison with other processes in the factory, where they were used without carbon tetrachloride, indicated that carbon tetrachloride was the offending agent. This conclusion was supported by the fact that the symptoms were similar to those described in the literature in mild forms of carbon tetrachloride poisoning and they were different from the known effects of the other chemicals.

Approximately 25 workers per shift were engaged on the plant and work was continued throughout the 24 hours on a three-shift basis, so that about 75 people were involved each day. Workers were often transferred to other parts of the factory so that the total number of people who had been exposed exceeded this figure. During the investi- 
gation we succeeded in interviewing and examining 78 of the factory employees: 51 of these were working on the carbon tetrachloride plant at the time of the examination and 27 were engaged on other processes but had been exposed previously. As many as possible of those examined were persuaded to have venepuncture and special investigations such as test meal, barium meal, gastroscopy and a detailed examination of the eyes by an ophthalmologist. The tests made on the sample of venous blood included a full blood count, erythrocyte sedimentation rate, blood urea, serum bilirubin and phosphatase, plasma proteins and the Takata-ara test for liver efficiency. Technical methods are described in a previous paper (Higgins, O’Brien, Stewart and Witts, 1943).
Another effect of exposure that had attracted the attention of the factory surgeon was a remarkable gain in weight in the women as soon as they began to work in the plant. When we came to examine the cases we found several instances of a gain of over two stone in a few months. This effect was most common in the women but was also found in a smaller number of the men.

\section{Gastro-Intestinal Effects}

The severity of the gastro-intestinal symptoms varied from a mild queasiness to violent and repeated attacks of nausea, vomiting, colic and diarrhoea. The more severe symptoms always followed a particularly heavy exposure such as might occur while attending to a big leak or spill. It was there-

TABLE 1

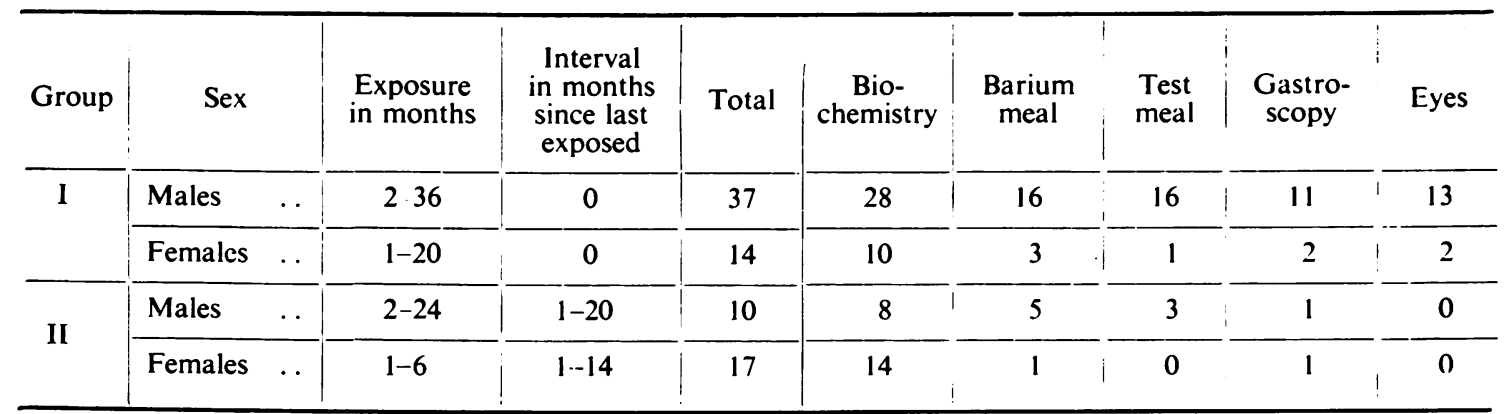

Number and sex of workers examined by various techniques. All were examined clinically. Workers in Group I were employed on the carbon tetrachloride plant at the time of examination. Those in Group II had been previously exposed but were now employed elsewhere in the factory.

Apart from one case of acute rheumatism, with aortic and mitral disease, two cases of essential hypertension, four cases of chronic bronchitis and emphysema, together with a fairly high incidence of minor defects such as gingivitis, dental caries, chloracne and folliculitis, clinical examination of the workers was essentially negative. It was a striking thing that despite the severity and duration of their symptoms the subjects had the appearance of good health. Their appearance almost belied their story. However, a typical history of symptoms resulting from exposure to carbon tetrachloride was obtained in every instance except one. The exception was a woman who had only recently been recruited to the work and had as yet experienced no ill effects. As the histories were related it soon became clear that there were two sharply differentiated sets of symptoms, one which indicated a gastro-intestinal disorder, and the other a cerebral disturbance. The certificates compiled by the factory surgeon contained the following list of complaints:

\begin{tabular}{|c|c|c|c|c|c|}
\hline $\begin{array}{l}\text { Nausea } \\
\text { Vomiting } \\
\text { Anorexia } \\
\text { Abdominal } \\
\text { Diarrhoea } \\
\text { Haemateme } \\
\text { Haemorrha } \\
\text { rectum }\end{array}$ & $\begin{array}{l}\ldots \\
\ldots \\
\ldots \\
\text { pain } \\
\ldots \\
\text { esis } \\
\text { ge } \\
\ldots\end{array}$ & $\begin{array}{rr}. . & 11 \\
. . & 12 \\
. . & 6 \\
. . & 7 \\
. . & 9 \\
. . & \\
\text { from } & \\
. . & \end{array}$ & $\begin{array}{l}\text { Weakness } \\
\text { Vertigo } \\
\text { Collapse } \\
\text { Confusion } \\
\text { Headache } \\
\text { Cough } \\
\text { Dyspnoea } \\
\text { Loss of wei }\end{array}$ & $\begin{array}{l}\ldots \\
\ldots \\
\ldots \\
\ldots \\
\ldots \\
\text { ight }\end{array}$ & $\begin{array}{l}\cdots \\
\cdots \\
\cdots \\
\cdots \\
\cdots\end{array}$ \\
\hline
\end{tabular}

fore characteristic for the symptoms to be recurrent rather than steadily progressive, though it was common for subjects to find that, whereas in the early weeks or months of exposure they felt well between the severe bouts, sooner or later they developed residual effects such as persistent nausea, alterations of appetite with a perverted sense of taste and smell, and a vague fullness in the epigastrium or dull ache in the lower part of the abdomen. Gradually they acquired such a distaste for the smell of carbon tetrachloride that they experienced attacks of vomiting in circumstances which had previously had no effect. In some cases sensitivity was heightened to an amazing degree. One of the fitters declared that he was unable to wear his gasmask because the smell of it induced vomiting immediately. A plant chemist volunteered the remark, 'I have now developed a conditioned reflex and the thought of setting about a job which involves handling the stuff is enough to make me vomit.' Others who had observed the same effect were convinced that their vomiting was now psychological, a possibility which was suggested on other grounds. It could not be supported as a total explanation, however, after one had considered the personality and record of many of the people. A few workers behaved in a different way. They remembered having had nausea and vomiting in the early days of exposure but in the end became immune and no 
longer suffered any ill-effects except when heavy contact with the fumes caused temporary giddiness and a feeling of intoxication, a narcotic rather than a gastro-intestinal effect. These workers were able to work in conditions considered intolerable by the others.

It was usual for subjects to experience nausea immediately after a period of heavy exposure but frequently vomiting was delayed until after the next meal and the attack often reached its climax after 24 hours, by which time, in severe cases, there might be extreme prostration with salivation, chilliness and shivering. On such occasions the vomit often contained streaks of blood and there was usually severe colic and diarrhoea.

Bowel symptoms were often most conspicuous in the first serious episode and might not be repeated in subsequent attacks. In two cases, however, they were the predominant feature and diarrhoea persisted for several weeks after the other symptoms had subsided. A mild recurrent form of diar rhoea was a very common residual effect, and it was significant that no single person working on the plant admitted to being constipated, though several had suffered in this respect before taking up their present work. Abdominal pain during the acute attacks was of two types and a worker might suffer from both or only one. Colic was both upper and lower abdominal and was of all grades of severity. The other type of pain was epigastric in situation, aching or burning in character, and persisted for longer periods than did the colic. It was described by one as grasping pain, by another as like a belt which is too tight. Though the liability to attacks increased, the severity usually did not, and one gained the impression that in spite of recurrent episodes there was no continuous deterioration in the general health. Even the residual symptoms that stretched from one exacerbation to the next were rapidly relieved after a brief period away from work.

Certain things accentuated the symptoms both between attacks and at the height of an episode. Many were found to be avoiding fat foods because they brought on nausea. Pickles caused pain. Milk, which was supplied freely and in abundance, was soon left untouched. Experienced workers never had beer before coming on a shift but one chemist said any long drink had a bad effect. Tobacco often heightened the nausea or the pain, and many experienced dizziness, palpitations, a feeling of coldness and even collapse when they smoked immediately after a shift. One intelligent young woman commented that the feeling carbon tetrachloride gave her was just like the feeling of being pregnant. 'You want to eat, but when you do, even a cup of tea tastes somehow different.'

\section{Mental Effects}

Temporary cerebral effects, such as light-headedness, giddiness and vertigo occurred immediately after exposure to high concentrations of carbon tetrachloride vapour, though there was considerable personal variation in the threshold at which symptoms appeared. A few individuals had lost consciousness whilst attending to leaks or spills. Acute headaches usually followed these events and a more chronic form of headache was found in several cases. Alteration of the sleep rhythm was as universal a complaint as were the gastro-intestinal effects. Drowsiness and failure to feel refreshed on waking were invariably present. Some said they could sleep the clock round and still want more; others, equally drowsy, had insomnia. Frequently one phase alternated with the other and in such cases temporary insomnia was often associated with the bouts of sickness. Excessive fatiguability as well as drowsiness was commented on by all.

The next commonest effect was a loss of mental agility which showed itself in inability to tackle more than one problem at a time and impatience with anything which demanded spontaneous enthusiasm. As might be expected, the mental hebetude which occurred as a result of exposure was more clearly described by the plant chemists and skilled workers than by the process hands. More than one plant chemist had noticed a time lag between thought and decision, and there was a tendency to loss of memory for recent events. Depression and irritability had often been remarked by the subjects. Inertia was such that one had diagnosed his complaint as pure idleness. Several said that they used to be voracious readers but were now liable to fall asleep over a book, or had such difficulty in following the plot and remembering fresh names, that they had given up reading books and only occasionally looked at the newspapers.

The need to clean and cook appeared to help the women, who were responsible for the care of their homes, to throw off the inertia which they felt as a result of contact with carbon tetrachloride, and several of them explained that a sleep of from half an hour to two hours immediately on returning home, before attempting to eat, made them feel fit enough to tackle household duties. Almost all workers interviewed said that they felt too lazy between shifts to make the effort to go out for air or exercise though they knew it would be good for them. As one man put it "The worst of the stuff is that it stops you doing what you know would do you good against it; you turn against milk and you can't be bothered with getting out of doors.' This comment came from a worker who had fished all the rivers within a radius of 40 or 50 miles and 0 knew in which the fish had survived the by-products of industry. After a few months on the plant he had completely dropped a hobby which had kept him sane all through the depression.

Other men, who had cultivated allotments during the same period, wished to keep them going but said they felt too lazy to make the effort after working with carbon tetrachloride. Many of the younger $\delta$ workers housed on a new estate had not even begun to get their gardens in order, but there was no means of knowing whether this neglect was more common 
among these workers than among other residents. The visitors had the impression that in spite of the opinion which most workers expressed that fresh air got rid of the effects of carbon tetrachloride and also that carbon tetrachloride and beer 'don't agree,' the workers often spent leisure time in the cinemas and public houses because it required less effort to do so than to get out for air and exercise. Nevertheless the speed with which symptoms disappeared when workers were removed from the plant was surprising. Almost all reported that a week-end away, especially if it was spent in exercise in the open air, caused great improvement in both mental state and gastro-intestinal symptoms. Even a long bicycle ride or a game of golf made a striking difference.

\section{Haematological and Biochemical Data}

Venous blood samples were obtained from 36 men and 24 women. The area from which the workers were drawn had suffered severely in the depression. For the ten years preceding the war there had been a great deal of unemployment and in some cases the unemployed were not reabsorbed into industry for twelve or eighteen months after the outbreak of war. Red cells and haemoglobin in both sexes are some 10 per cent. below the accepted standard of normality (Price-Jones, Vaughan and Goddard, 1935) but they are not significantly different from values obtained in nutrition surveys of comparable areas in 1942. The lowest haemoglobin value in a man was 81 per cent., but four of the women had haemoglobin values below 80 per cent. $-79,77,71$ and 67 per cent. respectively. The colour indices were unity or below. White cells are above the normal mean for venous blood, which Osgood, Brownlee, Osgood, Ellis and Cohen (1939) gave as $7410 \pm 70$. Sedimentation rates also are higher than Wintrobe and Landsberg's (1935) normals, but they are not very different from a group of controls from other sections of the factory. There is still a great deal to be learnt about the

TABLE 2

\begin{tabular}{|c|c|c|c|c|c|c|c|c|c|}
\hline & & No. & $\begin{array}{c}\mathrm{Hb} \text {, } \\
\text { per cent. }\end{array}$ & $\begin{array}{l}\text { R.B.C., } \\
\text { millions }\end{array}$ & C.I. & $\begin{array}{l}\text { W.B.C., } \\
\text { thousands }\end{array}$ & $\begin{array}{l}\text { Reticulo- } \\
\text { cytes, } \\
\text { per cent. }\end{array}$ & $\begin{array}{c}\text { E.S.R., } \\
\text { mm. }\end{array}$ & $\begin{array}{l}\text { Platelets, } \\
\text { thousands }\end{array}$ \\
\hline Males & $\ldots$ & 37 & $95 \pm 1 \cdot 14$ & $4.97 \pm 0.02$ & 0.97 & $10 \cdot 2 \pm 0.54$ & $1 \cdot 07 \pm 0.1$ & $9 \cdot 0 \pm 1 \cdot 22$ & i $247 \pm 3 \cdot 21$ \\
\hline Females & $\ldots$ & 24 & $86 \pm 1 \cdot 57$ & $4 \cdot 6 \pm 0 \cdot 1$ & 0.93 & $9 \cdot 1 \pm 0.52$ & $1 \cdot 49=0 \cdot 11$ & $18 \cdot 5 \pm 2 \cdot 6$ & $284 \pm 17 \cdot 8$ \\
\hline
\end{tabular}

Blood picture in chronic carbon tetrachloride intoxication. In this and subsequent tables the statistical averages are given \pm the standard error of the mean.

TABLE 3

\begin{tabular}{c|l|c|c|c}
\hline \multicolumn{1}{c|}{ Group } & Sex & No. & $\begin{array}{c}\text { Mean, } \\
\text { mm. }\end{array}$ & $\begin{array}{c}\text { Range } \\
\text { mm. }\end{array}$ \\
\hline $\begin{array}{c}\text { Medical students and } \\
\text { nurses (Wintrobe) }\end{array}$ & Males & 137 & $3 \cdot 7$ & $0-14$ \\
\cline { 2 - 5 } & Females & 100 & $9 \cdot 6$ & $0-29$ \\
\hline $\begin{array}{c}\text { Carbon tetrachloride } \\
\text { workers. }\end{array}$ & Males & 36 & $8 \cdot 5$ & $1-32$ \\
\hline $\begin{array}{c}\text { Unexposed workers } \\
\text { from same factory. }\end{array}$ & Males & 30 & $8 \cdot 2$ & $1-24$ \\
\cline { 2 - 4 } & Females & 19 & $11 \cdot 0$ & $4-31$ \\
\hline
\end{tabular}

Erythrocyte sedimentation rates in workers compared with normal men and women controls from the same factory. frequency distribution of haematological data in factory populations, but we feel justified in saying that there is no pathognomic change in the blood count of the carbon tetrachloride workers. The blood urea, the serum bilirubin and phosphatase, and the plasma proteins were all within normal limits. No individual value was significantly different from the normal, and the Takata Ara reaction was negative throughout. The total fats, fatty acids and cholesterol of the plasma were determined in 9 men and 12 women and these also were normal.

\section{Barium Meals}

Barium meals were performed on 25 subjects, 19 at present employed and 6 formerly employed on work with carbon tetrachloride. No one was seen during an acute attack of sickness but three subjects

TABLE 4

\begin{tabular}{|c|c|c|c|c|c|c|c|c|}
\hline & \multirow{2}{*}{ No. } & \multirow{2}{*}{$\begin{array}{l}\text { Blood urea, } \\
\text { mg. per } \\
100 \text { c.c. }\end{array}$} & \multirow{2}{*}{$\begin{array}{l}\text { Bilirubin, } \\
\text { mg. per } \\
100 \text { c.c. }\end{array}$} & \multirow{2}{*}{$\begin{array}{c}\text { Phosphatase, } \\
\text { King and } \\
\text { Armstrong } \\
\text { units }\end{array}$} & \multicolumn{3}{|c|}{ Proteins, g. per 100 c.c. } & \multirow{2}{*}{ Takata-ara } \\
\hline & & & & & Total & Albumin & Globulin & \\
\hline Males $\quad$. & 37 & $33 \cdot 8 \pm 0.96$ & $0.43 \pm 0.04$ & $9 \cdot 6 \pm 0.49$ & $7 \cdot 01 \pm 0.05$ & $4.5 \pm 0.04$ & $2 \cdot 53 \pm 0 \cdot 1$ & Negative \\
\hline Females .. & 24 & $30 \cdot 0 \pm 1 \cdot 17$ & $0.38 \pm 0.08$ & $9 \cdot 1 \pm 0.7$ & $6.99 \pm 0.06$ & $4.43 \pm 0.04$ & $2 \cdot 53 \pm 0.6$ & Negative \\
\hline
\end{tabular}


TABLE 5

\begin{tabular}{lr|r|r|r|r}
\hline & No. & $\begin{array}{r}\text { Total fats, } \\
\text { mg. per } \\
100 \text { c.c. }\end{array}$ & $\begin{array}{c}\text { Fatty } \\
\text { acids, mg. } \\
\text { per } 100 \text { c.c. }\end{array}$ & $\begin{array}{c}\text { Choles- } \\
\text { terol, mg. } \\
\text { per } 100 \text { c.c. }\end{array}$ \\
\hline Males &.. & 9 & $608 \pm 45$ & $346 \pm 40$ & $143 \pm 9 \cdot 8$ \\
Females &.. & 12 & $564 \pm 52$ & $380 \pm 63$ & $156 \pm 8 \cdot 4$ \\
\hline
\end{tabular}

Total fats, fatty acids and cholesterol in the plasma of carbon tetrachloride workers.

had some abdominal pain at the time of the examination and two had had a severe attack of vomiting a few weeks previously. The changes observed under the screen were similar in all the subjects examined. They were present even when there had not been any recent exposure, though the changes were then less marked. The abnormal features have been listed in Table 6 . They consisted of a characteristic change in the motility and appearance of the stomach and intestines, which suggested an unusual state of irritability and was shown chiefly by spasm of various parts of the gut and a rapid passage of the meal during the first six hours.

In all cases the stomach was of good tone and in three it was noticeably irregular in the prepyloric area. Four of these cases were examined with the gastroscope and this examination failed to reveal any evidence of ulceration which might have accounted for the appearance under the screen. Generally the mucosal folds were normal but in 7 cases they were less plastic than usual and the rugae appeared unduly prominent. In one of these the whole stomach seemed stiffened as though it had been infiltrated by some process that was impairing its normal elasticity. This appearance of thickening and irregularity of the wall with visible mucosal pockets was similar to that described with localized areas of chronic gastritis, but here again gastroscopy failed to reveal any abnormal surface changes.

The duodenal bulb was frequently abnormal. In no less than ten cases it was described as spastic and in six instances it was so exceptionally small that it gave the appearance of being in permanent tonic contraction. In addition, the mucosal folds of the bulb and the duodenal loop were often thicker and more rigid than usual. In spite of these appearances there was only one definite duodenal ulcer. This was seen as a small niche in the centre of the posterior wall.

Changes in the small bowel were present in nearly every case, for even where there was no irregularity or spasticity of the coils, there was hypermotility. In several cases the head of the meal was in the ascending colon at the end of one hour and in two cases it had reached the hepatic flexure. The changes in the mucosal pattern were not necessarily present throughout the whole of the small bowel. In some cases they were most marked in the duodenum and diminished in intensity towards the proximal coils of the jejunum. In others they were most severe in the terminal ileum.
Hypermotility was continued through the large intestine and in several instances the head of the meal had reached either the sigmoid colon or rectum at the end of six hours. Spasm of the colon was a conspicuous feature in all the cases in Group I but was absent in five of the six cases in Group II and in two of these cases the meal had only reached the hepatic flexure at the end of six hours.

TABLE 6

\begin{tabular}{|c|c|c|c|}
\hline & & $\begin{array}{c}\text { Group I } \\
(19 \text { cases })\end{array}$ & $\begin{array}{l}\text { Group II } \\
\text { (6 cases) }\end{array}$ \\
\hline $\begin{array}{l}\text { STомасн- } \\
\text { Hypertonicity } \\
\text { Prominent or rigid rugae } \\
\text { Excessive secretion } \ldots \\
\text { Pylorospasm ... } \\
\text { Irregular peristalsis } \ldots\end{array}$ & $\begin{array}{l}\cdots \\
\cdots \\
\cdots \\
\cdots\end{array}$ & $\begin{array}{r}3 \\
6 \\
8 \\
14 \\
5\end{array}$ & $\begin{array}{l}1 \\
1 \\
0 \\
3 \\
0\end{array}$ \\
\hline 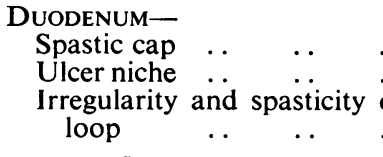 & $\begin{array}{l}\cdots \\
\ddot{o f} \\
\cdots\end{array}$ & $\begin{array}{l}8 \\
1 \\
7\end{array}$ & $\begin{array}{l}2 \\
0 \\
2\end{array}$ \\
\hline $\begin{array}{l}\text { JEJUNUM AND ILEUM- } \\
\text { Irregularity and spasticity } \\
\text { coils } \\
\begin{array}{l}\text { I. } \\
\end{array}\end{array}$ & $\begin{array}{l}\text { of } \\
\cdots\end{array}$ & 11 & 2 \\
\hline $\begin{array}{l}\text { Colon- } \\
\text { Spasticity: (1) Severe } \\
\text { (2) Moderate }\end{array}$ & $\begin{array}{l}\cdots \\
\cdots\end{array}$ & $\begin{array}{r}14 \\
5\end{array}$ & $\begin{array}{l}0 \\
1\end{array}$ \\
\hline 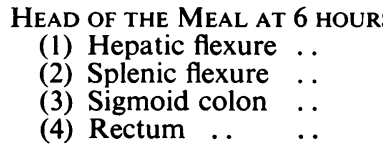 & $\begin{array}{l}\mathrm{RS}- \\
\cdots \\
\cdots \\
\cdots\end{array}$ & $\begin{array}{r}0 \\
5 \\
10 \\
4\end{array}$ & $\begin{array}{l}2 \\
2 \\
1 \\
1\end{array}$ \\
\hline
\end{tabular}

Radiographic findings in workers at present employed (Group I) or previously employed (Group II) in contact with carbon tetrachloride.

\section{Fractional Gastric Analysis}

Fractional test meals were carried out in 20 cases. The gastric stimulant was a pint of unsalted gruel and the secretion was followed for two-and-a-half hours. Judged by the standards of Bennet and Ryle (1921) hyperchlorhydria was present in 11 cases and hypochlorhydria in 3 cases. An excess of mucus was found in 3 cases. The most severe hyperchlorhydria was found in a man who had had a heavy exposure with severe nausea and vomiting five days before. Other examples of hyperchlorhydria were also associated with recent exposure. The group was comparatively small but it is striking that more than 50 per cent. showed excessive secretion of acid, in contrast to the 10 per cent. that might be expected, especially as many of them were middle-aged and elderly people. All the subjects with marked hyperchlorhydria showed considerable radiological changes, but these were also found in the presence of hypochlorhydria.

\section{Gastroscopic Examination}

Gastroscopy was carried out on sixteen workers, all of whom had also had a barium meal and follow- 
through examination. The examination was made with the Hermon Taylor gastroscope except in one man who had a slight scoliosis which necessitated using the Schindler gastroscope.

In nine cases there were well-marked disturbances of the musculature. The stomach was very tonic and did not allow easy inflation. The entrance to the antrum had a mouth-like appearance with the mucous membrane thrown into folds at its edge. It relaxed very slowly after inflation, and sometimes not at all. In two cases the mucous membrane of the antrum lay in longitudinal folds. Peristalsis was seen in half the cases, but in one the waves moved very slowly and passed only half-way up to the pylorus. Multiple rings of spasm were sometimes seen in the body of the stomach. The final impression was that the stomach was tonically contracted and unduly liable to intense and prolonged spasm.

In eleven cases, five of which had shown disturbances in tone, the mucous membrane was normal. In five the membrane was hyperaemic with a slight excess of high lights suggesting oversecretion or oedema. In eight cases there was a variable amount of exudate in the body of the stomach. This exudate was usually of the light frothy type, but in one case with a hyperaemic mucosa thick adherent mucus was seen in the antrum and lower part of the stomach, and cloudy bile-stained mucus was seen pouring back through the pylorus, carrying with it lumps of thicker yellowwhite mucopus. X-ray examination had revealed considerable irregularity of the mucosal pattern in the duodenum. In one other case, though the mucosa was normal in appearance, a small amount of mucopurulent exudate was seen in the region of the angulus. The largest amount of the white frothy exudate was seen in an individual who had had an attack of nausea and vomiting a few days previously and still had slight abdominal pain. Here the mucosa was normal but the angulus and sphincter muscle of the antrum were in intense spasm and the mucous membrane round it was thrown up into longitudinal folds.

The mucosal changes varied in type, occurred only in a minority, and with one exception were never severe. They represent minor degrees of gastritis and neither in incidence or severity are they more than might have been expected in any group of men or women of this age and class. On the other hand, the gastroscopic findings which have reference to the muscular wall of the stomach were all of the same type and occurred in over half the cases. They constitute the positive result of the gastroscopic investigations and are unusual findings. They support the conclusion that the gastric symptoms are the direct result of a motor disturbance, which may occur without any recognizable gastritis. The discovery of mucopurulent exudate in one case raises the suspicion that where disturbances in tone and secretion are continued for long periods they may eventually exert an irritant effect on the gastric mucosa.
TABLE 7

\begin{tabular}{|c|c|c|c|}
\hline Examination & & Group I & Group II \\
\hline $\begin{array}{l}\text { TeSt Meal- } \\
\text { Number of cases }\end{array}$ & $\begin{array}{l}\cdots \\
\cdots \\
\cdots\end{array}$ & $\begin{array}{l}19 \\
66: 5 \cdot 0 \\
56 \cdot 5: 6 \cdot 5\end{array}$ & $\begin{array}{r}1 \\
12 \\
0\end{array}$ \\
\hline 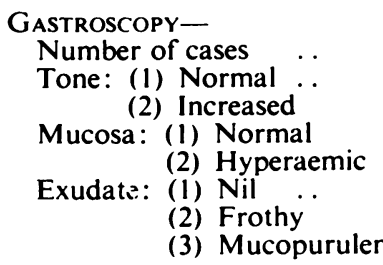 & $\begin{array}{l}\ldots \\
\ldots \\
\ldots \\
\ldots \\
\ldots \\
\ldots \\
\text { nt }\end{array}$ & $\begin{array}{r}13 \\
5 \\
8 \\
9 \\
4 \\
6 \\
5 \\
2\end{array}$ & $\begin{array}{l}3 \\
2 \\
1 \\
2 \\
1 \\
2 \\
1 \\
0\end{array}$ \\
\hline
\end{tabular}

Test meal and gastroscopic findings in carbon tetrachloride workers.

\section{Examination of the Eyes}

The fifteen cases examined from the visual point of view were submitted to the following tests:

1. Visual acuity without glasses, and with glasses when worn. If vision failed to improve to normal, the refraction was checked and vision recorded with an accurate correction.

2. Fields of vision recorded on the Lister Perimeter with a $\frac{1}{4}$-degree white object.

3. Investigation of the central field both for white and colours, Bjerrum Screen.

4. Ophthalmoscopic examination.

5. Ishihara test for colour vision.

The results can be summarized as follows :

(a) All cases had normal visual acuity, either without glasses, or with glasses where necessary.

(b) In all cases but one the fields of vision were full.

(c) All cases but one showed no scotomata and no enlargement of the blind spots and no scotoma for colour.

(d) Fundi were normal in all cases.

(e) All had normal colour vision save one, who had partial red-green deficiency. This he had always been aware of.

The one case who showed on the perimeter test a loss of field in the lower nasal quadrant of the right eye, on the Bjerrum Screen was found to have an arcuate scotoma arching downwards from the blind spot to the nasal side. Visual acuity was normal, and central colour perception acute. This man was 41 years of age and had been unaware of any visual disturbance. The field defect was rather suggestive of early chronic glaucoma, although there were no other signs. It was certainly not suggestive of any toxic condition.

\section{Follow Up}

Examination of the factory records revealed the fact that though no deaths had occurred from acute carbon tetrachloride poisoning, one male worker had died from a perforated gastric ulcer, one had been operated on for acute pancreatitis, five cases had developed albuminuria and one case had been 


\section{CHRONIC CARBON TETRACHLORIDE INTOXICATION}

found to have a large liver. In addition 86 individuals had been discharged for gastro-intestinal symptoms ascribed to carbon tetrachloride. The names and addresses of these individuals were obtained and an attempt was made to get in touch with as many as possible. In the end we succeeded in tracing three of the cases of albuminuria (two had left the district), the case of acute pancreatitis and the case of hepatomegaly, and they all attended for medical examination. In addition 54 houses were visited and 30 of the individuals discharged for sickness were seen in person by the health visitors. A specimen of urine was obtained from each. Six houses were empty and no further information was forthcoming. In 18 cases, though the individual was out at the time of the visit, it was ascertained from a neighbour or relative that he was either working full time or had joined the forces. No case of albuminuria was found amongst the 30 cases successfully visited and only six were not back at full-time work.

Two of these ascribed their ill-health to carbon tetrachloride sickness and were seen by the doctor. One had only left two weeks previously after a severe bout of vomiting and was already recovering and about to resume work, the other had had intense diarrhoea and had left the work six weeks previously. The diarrhoea had persisted for 4 weeks, and in addition he had lost 3 stones in weight and was extremely weak and breathless. $\mathrm{He}$ attended for a full examination including blood tests, barium meal and test meal. An x-ray film of the chest showed an extreme degree of emphysema and he was not considered a fit subject for gastroscopy.

Of the 4 remaining cases off work for reasons of health one was pregnant, two were over 60 years and had bronchitis and emphysema, and one was recovering from a recent attack of pneumonia.

The majority of the people interviewed had had gastro-intestinal symptoms for a variable length of time after leaving the factory. The chief complaint was nausea with disturbance of appetite and an intense dislike of any smell that reminded them of the chemical works. These symptoms had eventually passed off, and apart from the two cases mentioned above and one other individual who said that he had been more chesty since his discharge, no one thought he had suffered any permanent illeffects. Almost all had returned to full-time work in such strenuous occupations as coal-mining, munitions and aircraft work, a short time after their discharge and had remained in full working capacity. The average time interval since discharge was $10 \pm 7$ months.

The three cases of albuminuria were identical in that the urine had originally been free of albumin and its presence had been discovered at the routine medical inspections which were held at the factory each month. Though the subjects had experienced gastro-intestinal effects similar to those described in the group as a whole, there had been no other subjective evidence of ill-health. A trace of albumin was still present in the urine of all three but there was no disturbance of the blood chemistry or blood pressure. One man was working full time in another part of the factory, and one woman was doing all her housework and looking after her grandchildren. The other man was less fortunate in that he had developed a compensation neurosis and was rapidly becoming unemployable. He felt he had a financial grudge against the firm and devoted his whole time and energy to getting his insurance company to take legal proceedings. There was nothing on physical examination to suggest that he was not fit to do full-time work.

The only case of enlargement of the liver was discovered on clinical examination by the factory surgeon during a bout of diarrhoea and vomiting following carbon tetrachloride exposure. The man was referred to hospital where the finding was confirmed. There was no jaundice and he made an uninterrupted recovery from the gastro-intestinal disturbances. When seen by us he had been back at full-time work for two months. He looked well and his liver was no longer palpable.

The man with acute pancreatitis was admitted to hospital during a bout of vomiting that had begun three days previously, immediately after exposure to carbon tetrachloride. The vomiting was accompanied by intense abdominal pain. He was regarded as a surgical emergency and operation revealed an intensely congested haemorrhagic pancreas but no fat necrosis. The abdomen was closed without drainage and the patient made an uninterrupted recovery. When seen by us five months later he was back on a light job and felt well except that his appetite was still capricious. Clinical examination was essentially negative.

\section{Discussion}

As indicated at the beginning of this paper, the classical effects of carbon tetrachloride poisoning are narcosis, acute hepatic necrosis and acute nephritis. In our survey of over 170 men and women working in heavy contact with carbon tetrachloride only 1 case of enlarged liver and 5 cases of albuminuria were found, and all six recovered without any sign of progressive hepatic or renal disease. On the other hand, more than half the total 170 had been discharged or transferred from their employment on account of symptoms attributed to carbon tetrachloride poisoning. This suggests that in the past attention has been too closely concentrated on the lethal effects of carbon tetrachloride, and disabling symptoms have been neglected or misinterpreted.

Our investigation has shown that the characteristic symptoms of exposure to sublethal concentrations of carbon tetrachloride vapour are gastrointestinal distress and mental hebetude. The alimentary symptoms are associated with hypertonicity, irregular peristalsis and spasmodic contraction of the stomach and intestines, and with 
accelerated passage of the meal. They may be severe enough to simulate an acute abdominal emergency. The mental symptoms are characterized by lethargy and loss of mental agility, a subnarcotic effect. These symptoms are not associated with any physical signs of disease. In particular it may be noted that toxic amblyopia or restriction of the visual fields was not found, despite statements to the contrary (Wirtschafter, 1933).

Elkins (1942) was one of the first to comment on the occurrence of symptoms such as we have described in workers exposed to concentrations of carbon tetrachloride which had hitherto been considered harmless and which had produced little objective evidence of injury. $\mathrm{He}$ inclined to the view that they reflected the early stage of liver damage. The clinical picture revealed in our investigations, however, was not at all suggestive of hepatic or renal disease and the laboratory data did not indicate any impairment of function of these organs, in spite of prolonged exposure and the presence of symptoms in some cases for over twelve months. It is true that in a single individual normal liver function tests may not mean a great deal, but we know of no group of proved cases of diffuse disease of the liver in man in which the results of estimation of the serum bilirubin and phosphatase, the plasma proteins and the Takata-ara reaction, have been consistently negative. Further support to the view that the gastro-intestinal symptoms of carbon tetrachloride poisoning can be divorced from liver damage is given by Minot and Cutler's (1929) observation that in dogs given large doses of carbon tetrachloride, symptoms such as vomiting, diarrhoea, weakness and twitching are relieved by the administration of calcium but the damage to the liver is not reduced.

Studies of the effect of carbon tetrachloride on the liver in animals provide an explanation for the great rarity of chronic liver damage in man and suggest the reason why no lesions could be demonstrated in our cases, even though exposure might have been particularly heavy on occasion (Bollman and Mann, 1931; Cameron and Karunaratue, 1936). The changes produced in the liver by multiple administration of carbon tetrachloride depend on the size of the dose and the interval between successive doses. To bring about permanent liver damage there must be exposure sufficient to produce an immediate toxic effect and the dose must be repeated at short intervals. The acute lesion is always a fatty degeneration in the cells of the central and mid-zonal regions of the liver lobules. In the rat, repair of central necrosis is complete in fourteen days, and if the intervals between doses of carbon tetrachloride are spaced beyond this, the drug can be administered indefinitely without producing any alteration in the liver. If each dose of carbon tetrachloride is too small to produce changes in the liver, ne matter how frequently it is repeated, there will be no hepatic damage. In rats, even though the toxic dose is repeated often enough to produce extensive fibrous bands round the liver lobules, together with central necrosis and areas of regenerating liver tissue, the process may still be reversible and the liver may revert to normal on discontinuing the drug. After a certain time however, the cirrhotic changes become irreversible.

We must therefore look beyond the liver and the kidneys for an explanation of the mechanism of chronic carbon tetrachloride intoxication. The symptoms bear a strong resemblance to postanaesthetic sickness and recall the chemical relationship between carbon tetrachloride $\left(\mathrm{CCl}_{1}\right)$, chloroform $\left(\mathrm{CHCl}_{3}\right)$ and ethyl chloride $\left(\mathrm{C}_{2} \mathrm{H}_{;} \mathrm{Cl}\right)$. It is therefore possible that both the mental hebetude and the gastro-intestinal upset are due to an effect on the central nervous system and are explicable in terms of the narcotic action of carbon tetrachloride. Beattie, Brow and Long (1930) showed that chloroform exerts quite sharply localized effects on the sympathetic centres in the hypothalamus. We have been impressed by the resemblance between carbon tetrachloride intoxication and the gastro-intestinal effects produced by hypothalamic stimulation. Some of the protocols from Cushing's (1932) experiments, in which the hypothalamus was stimulated by the injection of pituitrin and acetyl choline into the lateral venticles, could be applied without alteration to carbon tetrachloride sickness.

"This was accompanied by pylorospasm and antiperistaltic waves leading to three attacks of vomiting. Each attack was accompanied by vigorous antiperistalsis. ... On the cessation of vomiting the tone of the stomach remained increased with prominent, apparently swollen rugae. In 20 minutes no visible trace of barium remained in the stomach, most of it being in the lower ileum. In one and onequarter hours the head of the barium column was in the hepatic flexure: no stool till following morning."

It is therefore suggested that mental hebetude is due to the effect of carbon tetrachloride on the cerebral cortex, and the gastro-intestinal symptoms are due to stimulation of the parasympathetic or inhibition of the sympathetic centres in the hypothalamus. Both effects can be paralleled by the known actions of chloroform. The fact that they are not due to hepatic or renal disease does not mean that we can afford to overlook their unpleasant nature and significance. The difference between the concentration of carbon tetrachloride which affects the central nervous system and that which affects the liver and kidneys does not seem to be large. If working conditions are such as to give rise to symptoms of chronic intoxication, the danger of acute lethal effects must be present. For this reason we hesitate to suggest any therapeutic indications for the treatment of chronic carbon tetrachloride poisoning. It is, in fact, the very occurrence and unpleasantness of the symptoms which has made carbon tetrachloride a relatively safe solvent, and to palliate them might be as harmful as taking the smell out of domestic coal-gas. 
The emphasis should therefore be placed on better design of plant, better ventilation, better use of masks. Recent experience at the factory under observation suggests that alternation of work, with successive weeks in and out of exposure to carbon tetrachloride, may improve efficiency when conditions of work cannot be made ideal.

\section{Summary}

1. A detailed examination has been made of workers at a factory in which exposure to carbon tetrachloride was heavy and persistent owing to wartime difficulties of ventilation.

2. Over a period of two-and-a-half years more than half the workers had been discharged or transferred to other employment on account of symptoms attributed to carbon tetrachloride poisoning.

3. Evidence of hepatic or renal damage was rarely obtained. The characteristic symptoms were mental hebetude and gastro-intestinal upset.

4. Investigation of the gastro-intestinal tract by fractional gastric analysis, radiography and gastroscopy, showed gastric hypersecretion, and hypermotility with accompanying irritability and irregular contraction throughout the alimentary tract.

5. No visual effects were detected.

6. The symptoms cleared up in a few days or weeks after removal from exposure, though some disturbance in the alimentary pattern might remain for some months.

7. It is suggested that both the mental hebetude and the gastro-intestinal upset are due to the action of carbon tetrachloride on the central nervous system.

This investigation was made possible by the Medical Research Council to whom we are indebted for a grant for technical assistance. In particular we wish to acknowledge the help of Professor A. W. M. Ellis of the Medical Research Council and Dr. A. I. G. McLaughlin of the Home Office. We should also like to thank the factory for much friendliness and co-operation. The following individuals took part in the investigation:

Miss H. E. Rees and Miss S. Habgood (social service) ; Dr. G. Malcolm Brown (gastroscopy); Dr. F. H. Kemp and Dr. J. A. Rose (radiology); Dr. W. J. W. Ferguson (ophthalmology); Miss E. Howes, Mr. G. Higgins, Miss P. E. Quelch and Mr. L. Rawlings (haematology and bio-chemistry).

\section{REFERENCES}

Beattie, J., Brow, G. R., and Long, C. N. L. (1930). Proc. roy. Soc., B, 106, 253.

Bennett, T. I., and Ryle, J. A. (1921). Guy's Hosp. Rep., 71, 286.

Bollmann, J. L., and Mann, F. G. (1931). Ann. intern. Med., 5, 699.

Cameron, G. R., and Karunaratue, W. A. E. (1936). J. Path. Bact., 42, 1.

Cushing, H. (1932). Papers relating to the pituitary body, hypothalamus and parasympathetic nervous sisiem. Springfield, Ill.

Elkins, H. B. (1942). J. industr. H.g., 24, 233.

Higgins, G., O'Brien, J. R. P., Stewart, Alice, and Witts, L. J. (1943). In publication.

Minot, A. S., and Cutler, J. T. (1929). J. clin. Invest., 6, 369 .

Osgood, E. E., Brownlee, I. E., Osgood, M. W., Ellis, D. M., and Cohen, W. (1939). Arch. intern. Med., 64, 105.

Price-Jones, C. I., Vaughan, J. M., and Goddard, H. M. (1935). J. Path. Bact., 40, 503.

Smyth, H. F., and Smyth, H. F. (1936). J. industr. Hyg., 18, 277.

Wintrobe, M. M., and Landsberg, J. W. (1935). Amer. J. med. Sci., 189, 102.

Wirtschafter, Z. T. (1933). Aner. J. publ. Hlth., 23, 1035 . 